\title{
BOMS: United Kingdom doctors in the Third World
}

\author{
C J BURNS-COX
}

In 1979 five doctors met to consider how to increase the number of United Kingdom registered doctors working in the Third World. Each believed that many doctors would like to help but lacked the knowledge of where help was needed and of working conditions in Third World countries. There were three problems to solve.

\section{Information required and provided}

Firstly, there needed to be a change in attitude to working in the Third World. Senior doctors, the royal colleges, and the Department of Health and Social Security should, through their training programmes, encourage doctors to go, while not of course discriminating against those staying behind. The returning doctor may well bring with him or her something extra that is a bonus to British medicine. The appointment system should be reviewed to take into account the problems of resettlement on return.

Secondly, doctors had difficulty finding when and where they were needed. This could be helped by a double register: one list of doctors keen to go and another of vacant posts.

Thirdly, doctors and their families needed information and sometimes training before going abroad. This could be provided by an advice pamphlet on work and life in the Third World, by putting doctors in touch with someone recently returned and by developing contacts with doctors and agencies who would be able to give the necessary training.

These problems seemed capable of solution and thus was born BOMS or the Bureau for Overseas Medical Service, which was soon given infant baptism by the Charity Commissioners. We found all sorts of people who either could not understand why such a bureau had not been formed before or had wished to set one up but had not had the opportunity. Everyone was most encouraging. The Commonwealth Foundation generously primed the pecuniary

Bureau for Overseas Medical Service, Africa Centre, London WC2E 8JT C J BURNS-COX, MB, FRCP, consultant physician pump, enabling us to start with a full time secretary/administrator and a temporary rented office in the London School of Hygiene and Tropical Medicine.

We soon became aware of the growing need for trained staff other than doctors. As there was no comparable organisation to arrange work overseas for these groups we began to expand to cover all types of health worker from physiotherapists to pharmacists and midwives to administrators. Our committee now includes three nondoctors. Eighteen months ago the Nuffield Foundation gave us support to continue this expansion of the register and to acquire a computer to run more efficiently. The register now has a growing number of a wide variety of health workers and the computer is now in full use. This has also been accompanied by a move into a new, more permanent office at the Africa Centre, Covent Garden, a lively spot and a relevant name, although our activities are world wide.

This adventure is great fun and exciting, not to say rewarding. For instance, we recently received a request from the International Rescue Committee in New York for two doctors to work in southern Sudan; within two days two British doctors had agreed to go. Just as quickly we were able to supply a medical officer for Tristan da Cuhna. We were also able to find pharmacists for Thailand and Zimbabwe at short notice.

Among those to whom I am grateful are the staff at the London School of Hygiene and Tropical Medicine, the Commonwealth and Nuffield Foundations, not to mention our lowly paid administrators, who have enabled BOMS to reach its fifth birthday with 1000 health workers on the register. One of our patrons is Maurice King, who wrote recently, "We have four and a half billion patients in the practice." Why should we ignore them by default?

\section{Response now}

If you have any suggestions for making the bureau more effective or would like to help in any way please telephone, write, or even better register and-as John Ebdon would say-if you have been, thank you for reading this.

\section{Insulin infusion pump}

\author{
SUSAN R DUNNETT
}

A young man, a stranger, was sitting next to me on the Greyhound bus travelling across America. As I gave myself a jab he asked if he could have one as well-thinking that it was heroin and not knowing that I was diabetic. Injections have plagued me since I was a child but now I am free of the inconvenience of daily or twice daily shots; hence this burst into print.

I have experienced many great advances towards improvement of the daily management of the condition: $27 \mathrm{G}$ disposable rather than reusable (for three weeks or more) $25 \mathrm{G}$ needles; disposable syringes

P O Box 785164, Sandton, Transvaal 2146, South Africa

SUSAN R DUNNETT, $\mathrm{MB}, \mathrm{CHB}$, anaesthetic registrar

Correspondence to: PO Box 429, Maseru, Lesotho 100, South Africa. graduated in units rather than the metal ones that were graduated in marks and had to be boiled and kept in surgical spirit-the marks often being a source of confusion for patients and sometimes nurses; an accurate painless pin prick blood sugar reading by Glucometer rather than testing the urine. Printing the calorie and carbohydrate values on packets of food has been helpful, but more important has been the awareness by the general public and employers that diabetics are not invalids but can lead a similar life, with minor modifications, to that of unafflicted people.

\section{Awkward methods}

Insulin injections have always been a tiresome part of my life and I fought for many years against twice daily ones despite the promise 